\section{The effects of olfactory and frontal pole lesions on the drinking response to hypertonic loading in rats}

\author{
W. GREGG WILCOVE* and W. B. VANCE \\ Indiana University, Bloomington, Ind. 47401
}

The drinking response to hypertonic loads can be depressed by frontal pole and/or olfactory bulb lesions. In order to evaluate the role of each of these structures, 36 rats were mechanically or electrolytically lesioned in the olfactory bulbs or frontal poles. Following hypertonic loading by IP injection of $\mathrm{NaCl}$, animals with olfactory lesions always drank like normal control animals, while animals with frontal lesions showed depressed, normal, or elevated drinking responses. These results were interpreted in relation to the known physiology of the hypothalamus and connections between hypothalamus and frontal poles.

The exact role of the frontal poles vs olfactory bulbs in the drinking response to hypertonic loading remains unclear as a result of recent experiments. IP injections of hypertonic $\mathrm{NaCl}$ solutions produce a cellular dehydration which is followed immediately by copious drinking. However, lesions in the olfactory bulbs (Vance, 1967) or frontal poles (Blass, 1968) have severely depressed this response to hypertonic stimuli, while leaving intact the animal's ability to regulate its daily water needs. Although both investigators report similar results, Vance's experiments implicate chiefly the olfactory bulbs (verified by gross inspection only) as the structure mediating the response to extracellular influences. Blass's results implicate the frontal poles or some interaction between olfactory and frontal tissue. From these two experiments, neither the olfactory bulbs nor frontal poles may be ruled out as a contributing source to the experimental results. Vance's lesions may have invaded the frontal poles, and Blass's lesions may have invaded olfactory tissue.

In more recent research, Glick (1971) demonstrated that removal of rat frontal cortex affects a modulation in ad lib food and water intake.

Both Blass's and Glick's research involved a massive removal of tissue. In these studies, the investigators report lesions extending posteriorly some 4-5 mm from the tip of the frontal poles.

Since Blass's lesions were extensive and may have resulted in damage to structures other than frontal cortex, this study was designed to assess the influence separately of the frontal poles and olfactory bulbs on the

*Requests for reprints should be sent to W. Gregg Wilcove, Psychology Department, Indiana University, Bloomington, Ind. 47401 . thirst-producing stimuli. Small discrete lesions involving only the olfactory bulbs or frontal poles were made. A variety of lesion techniques and locations were employed in investigating this phenomenon. All other procedural details were kept as close as possible to those used by Vance and Blass.

\section{METHOD}

The Ss were 41 male albino Holtzman rats, $120-180$ days old and weighing $400-550 \mathrm{~g}$. The rats were individually housed with ad lib food and water in a room kept on a 12-h day-night cycle. Water was available from a $100-\mathrm{ml}$ graduated cylinder affixed to the front of the cage.

All Ss were lesioned bilaterally either mechanically or electrolytically. The skull was trephined, using a hand-held twist drill, thus minimizing the possibility of edema from heat generated by drilling. Olfactory bulb lesions were produced by cutting the bulbs with scalpel or by electrolytic lesioning ( $1 \mathrm{~mA}, 20 \mathrm{sec})$. Frontal pole lesions were produced by aspirating tissue or by stereotaxic introduction of a bipolar electrode ( $1 \mathrm{~mA}, 20 \mathrm{sec})$.

Five groups of animals were prepared as follows: 6 mechanical olfactory (MO), 3 electrolytic olfactory (EO), 7 mechanical frontal polectomy (MFP), 20 electrolytic response to extracellular lesioned animals. frontal polectomy (EFP), and 5 unoperated controls (normal). Daily intake of water was monitored postoperatively prior to testing and in all cases was indistinguishable from that of normals by test day.

All Ss were tested at the same time of day, with a 1-M NaCl IP injection (2.0\% body weight) at least 7 days postoperatively, At least 1 week following this test, randomly selected Ss were injected with isotonic $(.9 \%)$ $\mathrm{NaCl}$ solution IP (2.0\% body weight). Readings of ad lib water intake were made at $15,30,60,90,120,150,180$, 210 , and $240 \mathrm{~min}$ postinjection. Readings were to the nearest milliliter, and food was absent during testing.

Following the last test, the animals were sacrificed and their brains placed in Formalin. Frozen sections were cut at 40 microns, mounted, and stained by the Nissl method, and lesions were evaluated without knowledge of the test results.

\section{RESULTS AND DISCUSSION}

The data were originally calculated in absolute milliliters drunk during testing. An additional analysis was performed on these data which were converted and expressed in milliliters $/ 100 \mathrm{~g}$ body weight. This analysis leads to the same conclusions and will be discussed later where appropriate.

Isotonic loads were ineffective in producing water intake in rats. None of the tested Ss, lesioned or control, drank in response to this stimulus. These data were omitted from further analysis.

Hypertonic loads always produced drinking in both $\mathrm{MO}$ and $\mathrm{EO}$ animals. However, EFPs and MFPs were about equally distributed between responding and not responding to the $\mathrm{NaCl}$ load. Further, the type of lesion was not correlated with the presence or absence of the response.

An analysis of variance of the drinking response to hypertonic stimuli was performed on three factors: type of lesion (electrolytic, mechanical, or none), location of lesion (frontal or olfactory), and time since injection (postinjection time). The results of this analysis indicated

Table 1

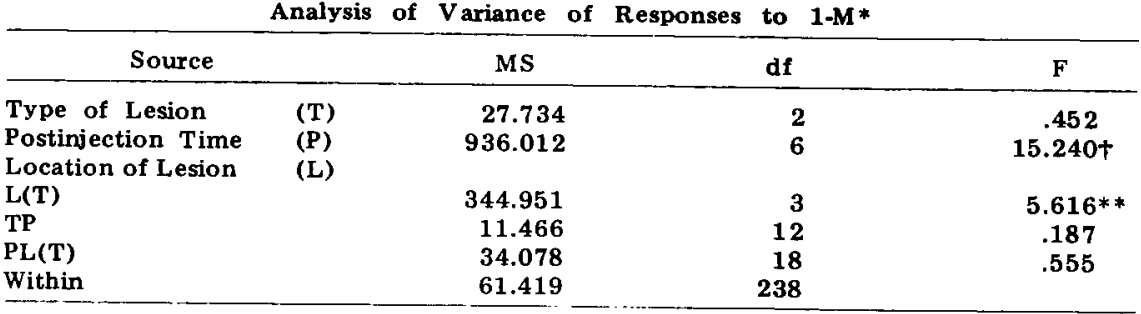

* NaCl injection was $2.0 \%$ of body weight in normal, frontally lesioned, and olfactory

$* * p<.01,+p<.001$ 


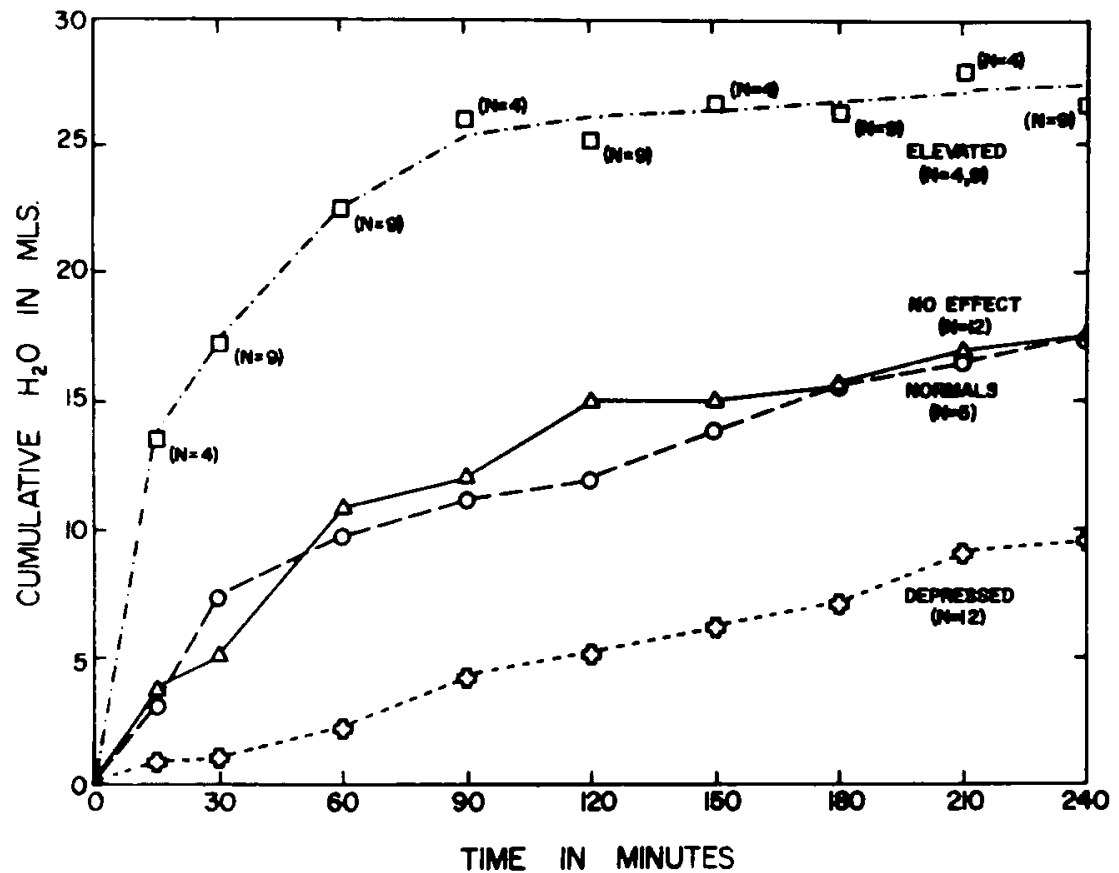

Fig 1. Mean cumulative $\mathrm{H}_{2} \mathrm{O}$ intake in milliliters for $\mathrm{Ss}$ grouped by response type (see text) following injection of $1 \mathrm{M} \mathrm{IP} \mathrm{NaCl}$ solution. Note that the elevated curve does not touch all points as the 15-, 90-min, etc., data points were not a vailable for all Ss. The curve was fitted by inspection.

that both postinjection time $(p<.001)$ and location of lesion nested in type of lesion $[\mathrm{L}(\mathrm{T})]$ $(\mathrm{p}<.01)$ were highly significant (see Table 1). No other main effect or interaction was significant. A Newman-Keuls test performed on the $\mathrm{L}$ ( T) factor identified the only significant difference as being between control animals and olfactory lesioned animals $(p<.05)$. This result can be accounted for by noting that olfactory animals always drank in response to the $\mathrm{NaCl}$ load, while frontal animals sometimes did respond and sometimes did not. Therefore, the olfactory bulbs may be ruled out as the structure mediating the depressed response to hypertonic stimuli.

The results of frontal pole lesions cannot be summarized as simply as the olfactory lesions. The post hoc test does not indicate a significant difference between frontals and controls; however, the inspection of individual responses suggests marked differences between Ss. Consequently, all lesioned animals were pooled into one large group irrespective of lesion and were then regrouped on the basis of individual responses to the hypertonic load. Unoperated control Ss were pooled, and their mean intake and range were calculated for 15-240 min. Then each experimental animal was sorted into one of three groups: above, within, or below the range of control Ss. If the lesioned animal fell within the range for control
Ss at any point, he was included as a no-effect $(\mathrm{N})$. This analysis yielded three distinct and separate groups with respect to controls: (1) equal, (2) elevated, or (3) depressed water intake $^{1}$ (see Fig. 1).

The Moses test of extreme reactions revealed that the resulting distribution of high-low experimental Ss around the control animals was significantly different from chance $(p=.006)$. This nonparametric statistic is sensitive to the number of control and experimental Ss and focuses on the span of the control cases. See Siegel $(1956$, p. 145$)$ for a more complete discussion. The distribution of lesion-type into response-type categories may be seen in Table 2 . Note that our depressed group of frontal Ss replicate Blass's initial findings in that the response to hypertonic $\mathrm{NaCl}$ has been severely depressed.

Using the grouping by response type of Ss, the four distributions (controls, elevated, depressed, and no effect) of
Table 2

Number of Animals Showing a Depressed. Normal, or Elevated Response as Compared to Control Ss Following a 1-M, 2.0\% Body Weight IP Injection of $\mathrm{NaCl}$

\begin{tabular}{lcccc}
\hline \multirow{2}{*}{$\begin{array}{c}\text { Amount Drunk } \\
\text { Relative to } \\
\text { Controls }\end{array}$} & \multicolumn{4}{c}{ Type of Lesion } \\
\cline { 2 - 5 } & MO & EO & MFP & EFP \\
\hline Depressed & 0 & 0 & 3 & 9 \\
No Change & 4 & 1 & 0 & 7 \\
Elevated & 2 & 2 & 4 & 4 \\
\hline
\end{tabular}

ad lib $\mathrm{H}_{2} \mathrm{O}$ intake for the 24 -h period immediately preceding the test were tabulated. A one-way analysis of variance was performed on these data, and there were no differences between groups $[F(3,37)=.34]$. Table 3 depicts the mean volumetric intake and standard deviation of the four groups as well as their group's body weight. Unfortunately, we did not collect data for the ad lib food intake or for the renal concentrating ability of these Ss.

In attempting to correlate lesion with behavior, no particular effect can be ascribed to a specific type or location of lesion. The results of the histologies confirmed that the electrolytic frontal lesions were small relative to Blass's and Glick's lesions and that in 31 of the 36 operated Ss, subcortical structures were not involved. Two of the Ss had been lesioned extensively in the preoptic area and were discarded (their data are not included); the other three suffered minor involvement of the dorsal aspect of the caudate nucleus and putamen. All three of these Ss gave a depressed pattern and are included in the data. Olfactory lesions produced a degeneration of the olfactory bulbs which projected into the olfactory tract and rhinencephalon. Ss whose frontal poles were aspirated were either depressed or elevated in their response; these lesions were more extensive than the electrolytically produced lesions, but still were confined to the cortex.

An analysis of area of lesion was undertaken in the electrolytic frontal group of animals. This group was chosen for this analysis as members of this group are represented in all three response categories (see Table 2 ).

The results of this analysis do not

Table 3

Mean and Standard Deviation of Water Intake for a 24-H Period of Ad Lib Food and Water for the Four Groups of Animals Sorted by Response Type to Hypertonic NaCl Loads

\begin{tabular}{lcccc}
\hline & Normals & $\begin{array}{c}\text { Equal to } \\
\text { Normals }\end{array}$ & Depressed & Elevated \\
\hline $\begin{array}{l}\text { Mean and SD } \\
\text { 24-h } \mathrm{H}_{2} \mathrm{O}\end{array}$ & $36.4 \pm 8.73$ & $36.4 \pm 8.98$ & $38.3 \pm 7.90$ & $39.63 \pm 6.52$ \\
$\begin{array}{l}\text { Mean Body } \\
\text { Weight }\end{array}$ & $438 \mathrm{~g}$ & $448 \mathrm{~g}$ & $454 \mathrm{~g}$ & $450 \mathrm{~g}$ \\
\hline
\end{tabular}


aid in isolating the variable which separates the three response types. However, several points concerning the lesions should be noted. Animals showing the normal response have, in general, a set of lesions which do not involve the frontal poles and which seem to be more posterior than either of the other two response-type lesions (see Fig. 2). If the separation between the anterior border of the lesion and the tip of the frontal poles is measured, no-effect Ss average $2.91 \mathrm{~mm}$ distance, while all others average $1.38 \mathrm{~mm}$. Secondly, although statistically nonsignificant, elevated-response animals have smaller lesions than depressed-response animals (mean area, $3.74 \mathrm{~mm}^{2}$ vs $6.64 \mathrm{~mm}^{2}$ ), and the present depressed-response animals replicate Blass's (1969) findings. This would indicate that a "large" lesion may be a major factor in producing a depressed response. Lashley's (1929) law of mass action, coupled with the fact that the frontal cortex of the rat is a motor area (Woolsey, 1958; Woolsey et al, 1950; Leonard, 1969), suggests the possibility that the depressed response is due to a motor dysfunction. However, this can account for neither the elevated response nor the animals' ability to regulate adequately their diurnal needs.

More attractive, but undocumented, is the hypothesis that the results of the present experiment can be accounted for by mechanisms which are already known to exist in the hypothalamus. Blass's frontal pole lesions demonstrated a separation of cellular and extracellular influences on drinking; Verney demonstrated the effect of hypertonic stimuli on the hypothalamus in 1940 . In more recent research, Blass showed that frontally lesioned animals evince a hyperthermia which is manifested physiologically as well as behaviorally (Blass, 1971). Magoun (1938) demonstrated the role of the hypothalamus in heat regulation. And finally, Glick accounted for his results in terms of an osmoreceptive unit disturbed by frontal lesion-a unit already known to be functioning in the hypothalamus (Glick, 1971). Frontal pole lesions affect food, water, and thermal regulation in the rat, phenomena more usually associated with hypothalamic functioning (Brobeck et al, 1943; Andersson \& Wyrwicka, 1957; Magoun et al, 1938).

The frontal poles seem to share connections with hypothalamic structures. Domesick (1969), in a degeneration study of cingulate cortex of the rat, noted connections to some hypothalamic nuclei, and Leonard (1969) found similar results. Neither study implicates strong connections
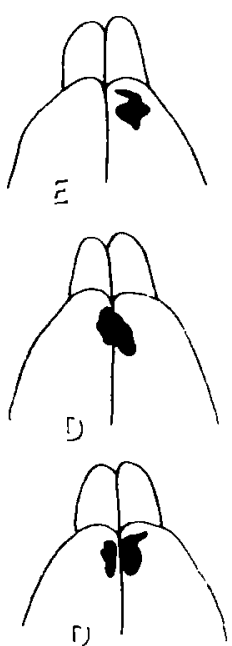

()
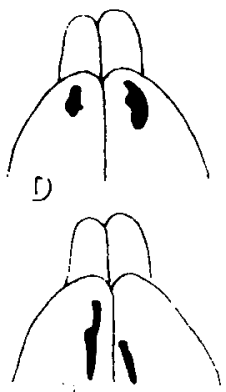

Fig. 2. Electrolytic frontal pole lesions, dorsal aspect: $\mathbf{E}=$ elevated response, $D$ = depressed, and $N$ = no effect (see text for full explanation of response type). Redrawn from Zeman \& Innes (1963).

existing between the hypothalamus and the frontal isocortex. However, these connections cannot be ruled out, particularly in light of the behavioral data.

Finally, hypothalamic lesions can be responsible for an elevation, as well as for depression of drinking. Secondary polydipsias due to dehydration from diabetes insipidus can be traced to damage in the hypothalamic-pituitary system, and primary polydipsias in birds resulting from hypothalamic lesions have been reported by Wright (1969) and Kuenzel \& Helms (1970).

It is possible that our results were due to degeneration in frontohypothalamic pathways or secondary degenerative changes in the hypothalamus. That the hypothalamus is composed of mutually exclusive excitatory and inhibitory centers is known; it is possible that the depressed, elevated, and no-effect responses resulting from frontal pole lesions may be traceable to hypothalamic damage in "appropriate centers."

There is no doubt that the frontal poles rather than olfactory bulbs are responsible for the aberrant response to hypertonic loading. The factors controlling the elevation or depression
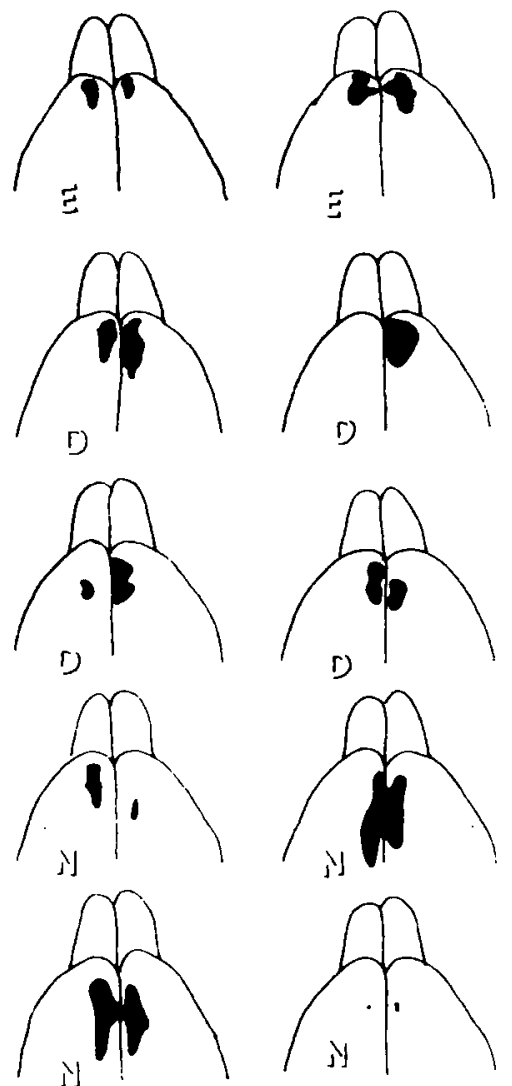

of the drinking response are as yet unclear.

\section{REFERENCES}

ANDERSSON, B. Studies on the thirst mechanism. Acta Biologiae Experimentalis, 1967, 27, 269-275.

ANDERSSON, B. \& WYRWICKA, $w$ Elicitation of a drinking motor reaction by electrical stimulation of the hypothalamic "drinking center" in the goat. Acta Physiologica Scandinavica, $1957,41,194$.

BLASS, E. Separation of cellular from extracellular controls of drinking in rats by frontal brain damage. Science, 1968 , 162, 1501-1503

BLASS, E. Effects of frontal pole ablation on temperature regulation in the rat. Journal of Comparative \& Physiological Psychology, 1971, 74, 233-239.

BROBECK, J. R., TEPPERMAN, J., \& LONG, C. N. H. Experimental hypothalamic hyperphagia in the albino rat. Yale Journal of Biological Medicine, $1943,15,831-853$.

DARROW, D., \& YANNET, $H$. The changes in distribution of body water accompanying increase and decrease in extracellular electrolyte. Journal of Clinical Investigations, $1933,14$. 266-275.

DOMESICK, V. B. Projections from the cingulate cortex in the rat. Brain Research, 1969, 12, 296-320.

GLICK, S. Modulation of food and $\mathrm{H}_{2} \mathrm{O}$ intake by frontal cortex in rat. Communications in Behavioral Biology,

KUENZEL, W. J., \& HELMS, C. W Hy perphagia, polydipsia, and other $1971,5,365-370$. 
effects of hypothalamic lesions in the white-throated sparrow, Zonotrichia albicollis. Condor, 1970,72, 66-75.

LASHLEY, $K$. S. Brain mechanisms and intelligence. Chicago: University of Chicago Press, 1929

LEONARD, C. The prefrontal cortex of the rat. Brain Research, 1969, 12, 312-343.

MAGOUN, H. W., HARRISON, F. BROBECK, J. R., \& RANSON, S. W. Activation of heat loss mechanisms by local heating of the brain. Journal of Neurophysiology, 1938, 1, 101-114.

SIEGEL, S. Nonparametric statistics for the behavioral sciences New York McGraw-Hill, 1956. Pp. 145-152.

VANCE, W. Olfactory bulb resection and water intake in the white rat. Psychonomic Science, 1967, 8, 131.

VERNEY, E. T. The anti-diuretic hormone and the factors which determine its release. Proceedings of the Royal Society, (London) B, 1940, 135, 25-106.

WOLF, A. V. Osmometric analysis of thirst in man and dog. American Journal of Physiology, 1950, 161, 75-86.

WOOLSEY, $\dot{C}$. Organization of the somatic sensory and motor cortex areas of the cerebral cortex. In $H$. F. Harlow and $C$. Woolsey (Eds.), Biological and Woolsey (Eds.), Biological and
biochemical bases of behavior. Madison: University of Wisconsin Press, 1958.

WOLLSEY, C., SETTLAGE, P. H., MEYER, D. R. SENSOR, W., HAMUY, T. P., \& TRAVIS. A. M. Patterns of localization in precentral and "supplementary" motor areas and their relation to the concept of a pre-motor area. Vol. XXX. Patterns of organization in the CNS. Proceedings of the Association for Research in Nervous \& Mental Disease, New York, December 15 and $16,1950$.
WRIGHT, P. , \& McFAKLAND, D. Functional analysis of hypothalamic polydipsia in the Barbary done. Physiology \& Behavior, 1969, 4, 877-883.

ZEMAN. W., \& INNES, J. R. Craigie's neuroanatomy of the rat. New York: Academic Press, 1963.

$$
\text { NOTE }
$$

1. The data from this analysis were converted into milliliters intake $/ 100 \mathrm{~g}$ body weight, which resulted in an identical set of curves as in Fig. 1. However, one or two scores overlapped at various points on these converted functions. Therefore, a one-way analysis of variance was performed on these four groups at their worst point of overlap (30 $\mathrm{min}$ ) and the resulting difference was still highly significant $[F(3,37)=34.67$, $\mathrm{p}<.001$ ] . Consequently, only the absolute intake data are presented. 